\title{
Providing Processing of Complex Surfaces by Cutting on Machines Equipped with a Valve Electric Drive with an Information and Measuring System
}

\author{
Sergey Ambrosimov ${ }^{1}$, and Viktor Meshcheryakov ${ }^{1,}$, Elena Gracheva ${ }^{2}$ \\ ${ }^{1}$ Lipetsk State Technical University, Lipetsk, Russia \\ ${ }^{2}$ Kazan State Power Engineering University, Krasnoselskaya st,. 51, 420066 Kazan, Russia
}

\begin{abstract}
Promising methods of metal processing by cutting the surface of complex parts are considered. To ensure high productivity when processing complex surfaces on CNC machines, the tool is provided with additional high-speed complex-coordinated movements that ensure the displacement of the cutting edge relative to the cutting surface. The offset of the cutting edges relative to the cutting zone during milling reduces the temperature load on the teeth and, as a result, increases the tool's durability. The faster the cutting edge leaves the cutting zone, the lower the heat load and the higher the wear resistance of the cutters. In this regard, it is important to increase the speed and accuracy of movements of the working bodies of the machine. To implement the required characteristics when performing technological operations, it is proposed to use an AC electric drive system based on a valve motor with vector control and an information and measurement system containing variable sensors, which has better technical, economic and mass-dimensional indicators compared to other types of electric motors. The results of computer simulation of dynamic processes of regulating the speed and torque of a valve engine that provide the required dynamic torque and acceleration are presented. It is shown that an AC electric drive based on a valve motor provides the implementation of the required speed modes.
\end{abstract}

\section{General information}

Modern multi-axis CNC machine systems have capabilities that are not used effectively enough in terms of increasing productivity and tool durability, for example, by changing the kinematics or the accuracy and speed of mutual movements of the working bodies of the machine. These conditions are currently most effectively provided by an AC electric drive based on a valve control.

The task of increasing the productivity of mechanical processing is solved by various methods; the use of highstrength tool materials, coatings, cooling media. Milling is one of the most productive processing methods due to the high concentration of cutting edges simultaneously involved in the work. The development of new milling methods in recent years has been due to the improvement of kinematics. This led to the creation of processing methods such as milling, plunger milling, and others. The shape of the processed surface, the thickness and length of the cut metal layer, the processing performance and the concentration of heat generated on the cutting edge sections depend on the ratio of movement speeds. Milling of dies, molds, and large-scale gears is associated with large volumes of material being removed, which increases the cost of expensive cutters.

When processing some complex surfaces, a certain ratio between shaping movements or alignment is important. The ratio between the shaping movements can increase the length of the cutting edges, reduce heat load and wear. The ability of modern machines to coordinate simultaneous movements is practically unlimited, but these principles are not often used in the development of new technologies. Methods with time-varying ratios of the speeds of forming movements can be attributed to the second level of agreement. When processing complex surfaces, blades of screws, turbines, stamps, processing is carried out in lines according to the program or a copier, for example, end radius cutters, while in each milling plane, the ratio between the two movements changes depending on the shape of the profile in the section being processed, i.e. the movements agree non-linearly (Fig. 1). When the tool is moved line by line in the processing plane, the relationship between the feed movements on the $O X$ axis and on the $O Y$ axis constantly changes. For example, from point $A$ to point $A 1$, the amount of tool movement along the $O X$ axis is less than the movement along the $O Y$ axis, and from point $A 1$ to point $A 2$, the amount of movement along the $O X$ axis is greater than the movement along the $O Y$ axis. In some cases, to prevent zero cutting speeds near points $(A 3)$ where the tool axis is perpendicular to the surface to be processed, another movement is added - the rotation of the workpiece in the $O X Y$ plane, resulting in the workpiece being tilted at a certain angle in the processing plane relative to the tool. In this case, it is necessary to coordinate three shaping

Corresponding author: mesherek@yandex.ru 
movements, two feed movements along the axes $O X$ and $\mathrm{OY}$, and the rotation movement in the plane $O X Y$.

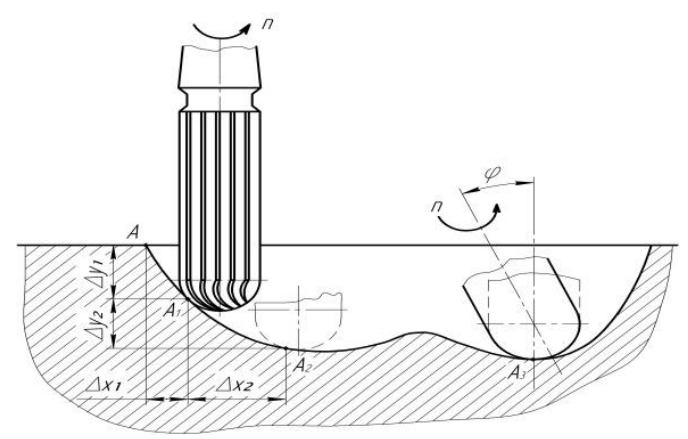

Fig. 1. Scheme of processing a complex surface with an end radius milling machine.

In recent years, new processing methods have emerged that use three simultaneous non-linear coordinated movements for processing complex surfaces $[1,2,3,4,5,6,7]$, both in the same profiling plane and in different, for example, mutually perpendicular ones. Processing with three simultaneous non-linear coordinated movements can be used to form complex profile surfaces, such as gears of various profiles and other parts with a periodically repeated complex profile.

However, the main purpose for some of these methods, in addition to the above, is: a) to ensure consistent contact of a simple tool shape with all points of the processed profile, b) a constant displacement of the cutting edge vertex relative to the cutting surface.

Advanced in this regard are milling methods with additional shaping movements that ensure constant movement of the cutting edge relative to the cutting surface.

Let's consider options for milling a shaped profile of an annular shape with a rotating cylindrical cutter. For example, processing a rotation body with convex repeating curved sections can be performed with a rotational main movement $\mathrm{Dr}$ and two coordinated feed movements: the rotation of the cutter (turning the table) $D \omega$ and the longitudinal movement of the caliper $D s$. These movements must be coordinated in such a way that when the cutter is rotated at an angle of $90^{\circ}$, the table moves along the entire width of the curved section $B$. However, in this case, it is not possible to ensure a constant radius of the curved section. That is, to ensure a radius section, the milling cutter, depending on the position of the touch point, must move not only along the $X$-axis, but also along the $Y$-axis (Fig. 2). Thus, three coordinated movements must be provided simultaneously $D \omega, D s x$ and Dsy. The movements must be coordinated, so that when moving the cutter to a certain point $i$ in the profile, the cutter must turn by an angle $\Delta \varphi \cdot i$ and its touch point will move by $\Delta a \cdot i$ an amount.

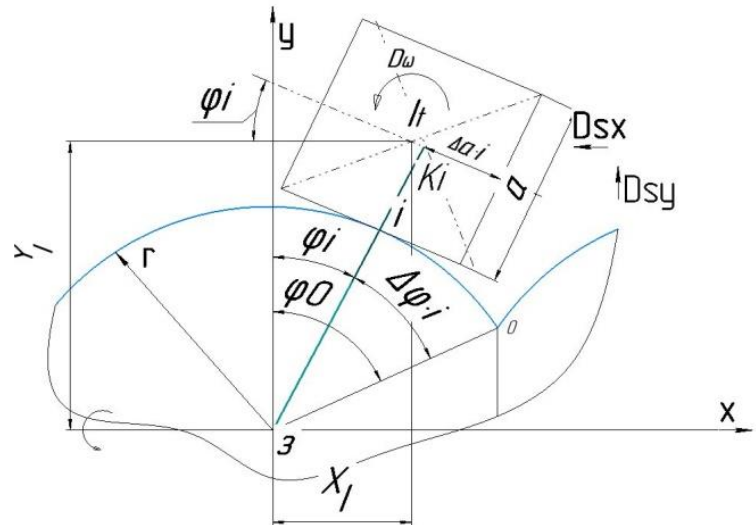

Fig. 2. Scheme of processing the shaped surface by milling with three non-linear movements of shaping and moving the cutting edge relative to the cutting surface.

Where, $\Delta \varphi$ - is the discrete angle for calculating displacements $X_{I}, Y_{I} ; \Delta \varphi=\frac{\varphi_{0}}{n}$,

$n$ - the number of touch points on the processed section of the profile,

$a$ - length of the mill section in the axial direction for processing the profile arc with an angle $\varphi_{0}$.

To improve milling efficiency, the speed of rotation of the cutter $D \omega$ must be maximum, so as to ensure the maximum possible displacement of the upper part of the cutting edge relative to the cutting surface. This allows you to quickly shift the high-temperature zone relative to the cutting edge and, as a result, increase the wear resistance of the tool. Increasing the processing speed $D \omega$ requires, on the one hand, reducing the allowance, i.e., the reciprocating movement of the tool, and on the other hand, increasing the speed of the translational movements Dsx and Dsy, since they are consistent with $D \omega$. Thus, the offset of the cutting edge in combination with non-linear rolling of the tool when processing complex profile surfaces requires the use of precise and high-speed drives.

\subsection{Mathematic model}

The specified requirements are fully met by an AC electric drive system based on a valve motor, which is a synchronous motor with permanent magnets with a rotor position sensor powered by a frequency Converter. The frequency Converter is mainly based on a voltage inverter. The electric drive is controlled by a vector system, the functional scheme of which is shown in Fig. 3. 


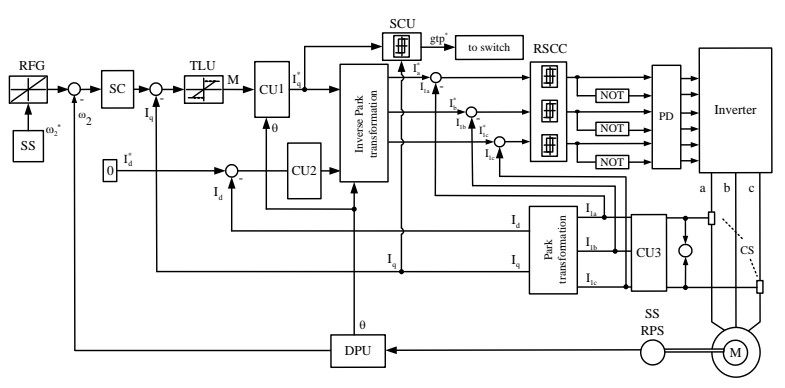

Fig. 3. Functional diagram of vector control of an electric drive.

The functional diagram of an electric drive contains the following main elements: $\mathrm{M}$ - permanent magnet synchronous motor; RFG -ramp function generator; RPS - rotor position sensor; SS - speed selector sensor; CS - current sensors; RSCC - relay stator current controller, SC - speed controller, CU1, CU2, CU3 - calculating units; PD - pulse distributor, TLU torque limiter unit; DPU - data processing unit.

The systems of the valve electric drive, as a result of the use of a frequency Converter with a voltage inverter and an unregulated rectifier, have good electromagnetic compatibility with the supply network $[8,9,10,11]$. High-quality control of the output variables of the electric drive-speed and torque, is provided by the use of a group of sensors of electric drive variables that are part of the information measuring system. If necessary, the vector control system can be supplemented with corrective devices $[12,13,14]$ that affect the process of forming the speed and torque of the electric drive, depending on the nature of the processes that occur in the Metalworking of complex parts.

Figure 4 shows graphs of transient changes in output variables-speed and torque of the valve motor, obtained by computer simulation using the software product MATLAB [15], SimPowerSystems and Simulink, for the system (Fig. 3).
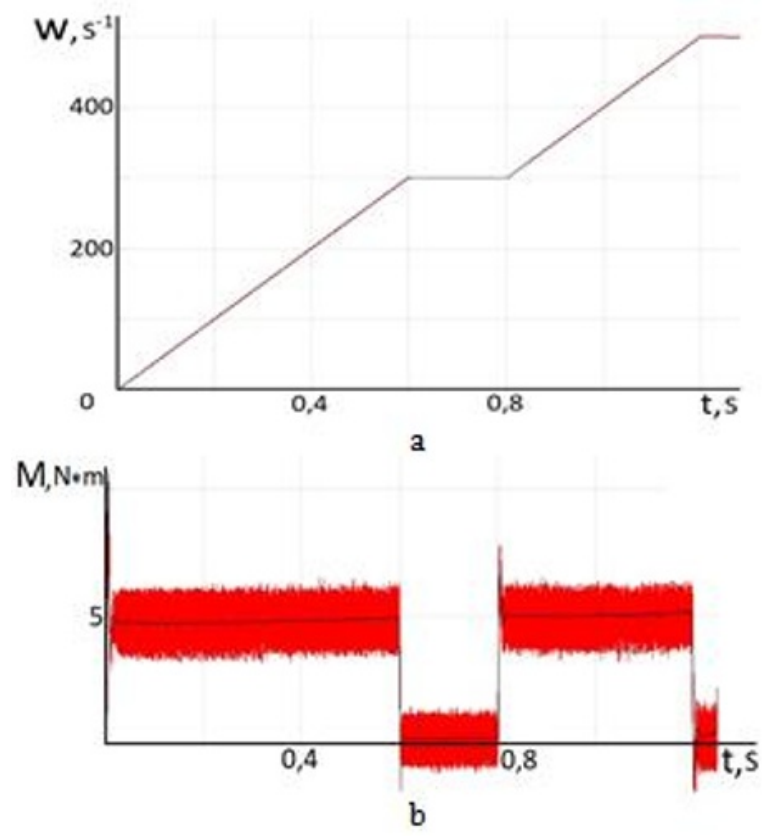

Fig. 4. Time diagrams of changes in the speed (a) and torque (b) of the valve motor.
The obtained graphs show that the electric valve drive is able to provide the required speed modes and forces to ensure the processing of complex profile surfaces on metal-cutting machines.

\section{Conclusion}

Modern requirements for the quality of Metalworking of complex parts require the development and application of new methods that can be implemented using systems of controlled electric drive based on a valve motor that has acceptable dynamic properties.

\section{References}

[1] S.K. Ambrosimov, A.A. Petrukhin, A method for processing curved surfaces, Pat. no. 2167746 (RF), Byul., 15 (2001)

[2] S.K. Abrosimov, M.G. Stegkin, Method of processing shaped concave surfaces, Pat. no. 22008502 (RF), Byul., 20 (2003)

[3] S.K. Ambrosimov, K.S. Ambrosimov, Method of screw black-and-white milling of shaped surfaces, Pat. no. 2344023 (RF), Byul., 2 (2009)

[4] S.K. Ambrosimov, A. Zhirkov, Milling complex surfaces with cutting edge displacement towards the cut surface, IOP Conf. Series: Materials Science and Engineering 124, $012002 \quad$ (2016) DOI: 10.1088/1757-899X/124/1/012002

[5] S. Ambrosimov, G. Harlamov, A. Cherepenko, Kinematic Model of Complex Surfaces Formation with Three None Linear Movements Forming, Procedia Engineering, International Conference on Industrial Engineering - 2016 150, 1089-1097 (2016)

[6] S.K. Ambrosimov, A.V. Khandozhko, Metal cutting of tooth gears by a method of a nonlinear generating process of a profil, 2017 IOP Conf. Series: Materials Science and Engineering 177, 012050 (2017) DOI: 10.1088/1757-899X/177/1/012050

[7] S.K. Ambrosimov, A.V. Morozova, Investigation of formation of cut off layers and productivity of screw milling process, IOP Conf. Series: Materials Science and Engineering 327, 042003 (2018) DOI: 10.1088/1757-899X/327/4/042003

[8] Y.I. Gracheva, N.A. Alimova, Calculating Methods and Comparative Analysis of Losses of Active and Electric Energy in Low Voltage Devices, International Ural Conference on Electrical Power Engineering (UralCon), 361-367 (2019)

[9] Y.I. Gracheva, O.V. Naumov, Estimation of Power Losses in Electric Devices of the Electrotechnical Complex, International Conference on Industrial Engineering, Applications and Manufacturing (ICIEAM), 6 (2019)

[10] V.N. Meshcheryakov, V.V. Danilov, Sh.R. Khasanov, S. Valtchev, Minimization of the stator current in induction motor with defined load 
on the shaft by maintaining optimum absolute slip, Kazan, SES 2019, E3S Web of Conferences, 01036 (2019)

[11] V.N. Meshcheryakov, D.V. Lastochkin, Z.M. Shakurova, S. Valtchev, Energy saving system of frequency-cascading asynchronous electric drive, Kazan, SES 2019, E3S Web of Conferences, 01037 (2019)

[12] Bimal K. Bose, Modern Power Electronics and AC Drives, Upper Saddle River (NJ, Prentice-Hall, 2002)

[13] L. Ting, Y. Tan, G. Wu, W. Shumao, Simulation of PMSM vector control system based on matlab / Simulink, Proc. IEEE Int. Conf. Measuring Technology and Mechatronics Automation (ICMTMA09) 2, 343-346 (2009)

[14] A.S. Anuchin, Control systems of electric drives: textbook for higher education institutions (Moscow, MEI publishing house, 2015) 373

[15] S.G. Herman-Galkin, Virtual laboratories of semiconductor systems in the environment of Matlab-Simulink: Textbook (Saint-Petersburg, Lan publishing house, 2013) 448 